\title{
AUTORITARISMO VERSUS REDEMOCRATIZAÇÃO: DO IMIGRANTE NO BRASIL
}

\author{
Mateus de Oliveira Fornasier* \\ Maiquel Angelo Dezordi Wermuth ${ }^{* *}$
}

SUMÁRIO: Introdução; 2 Segurança Nacional e Utilitarismo como Subterfúgios para o Desamparo do Estrangeiro; 3 Constituição e Teoria dos Sistemas Autopoiéticos; 4 Pragmática Includente dos Direitos Humanos e Fundamentais; 5 Considerações Finais; Referências

RESUMO: Este artigo analisa a evolução da política de imigração brasileira, focandose nos reflexos da doutrina da segurança nacional à legislação brasileira. Investigouse, nesta senda, que características podem ser atribuídas ao (des)respeito aos direitos fundamentais dos estrangeiros, sendo considerada a ordem constitucional de 1988. Resultou-se que, apesar do grande progresso na semântica constitucional referente ao significado da dignidade humana, verificou-se, no Estatuto do Estrangeiro brasileiro, uma continuidade da discriminação, da discricionariedade do Poder Executivo, e do choque entre esta lei e os objetivos do Estado brasileiro instituídos na Constituição.

PALAVRAS-CHAVE: Direitos Fundamentais; Estatuto do Estrangeiro; Inclusão; Segurança Nacional.

\section{AUTHORITARIANISM VERSUS RE-DEMOCRATIZATION: THE IMMIGRANT IN BRAZIL}

\begin{abstract}
The evolution in Brazilian immigration laws is analyzed with special focus on the effects of the doctrine of National Security on Brazilian law. The characteristics that may be attributed to the (lack) of respect to the basic rights of foreigners are investigated, taking into consideration the 1988 Constitution. In spite of great progress in the interpretation of the Constitutional on human dignity, the Brazilian Statute of the Foreigner is still rife with discrimination, the discretion of the government and the conflict between the law and the aims of the Brazilian State instituted by the Constitution

\footnotetext{
Doutor em Direito Público pela Universidade do Vale do Rio dos Sinos (UNISINOS); Docente do Programa Pós-Graduação Stricto Sensu em Direitos Humanos da Universidade Regional do Noroeste do Estado do Rio Grande do Sul (UNIJUÍ), Ijuí (RS), Brasil; E-mail: mateus.fornasier@gmail.com ma Pós-Graduação Stricto Sensu Direitos Humanos da Universidade Regional do Noroeste do Estado do Rio Grande do Sul (UNIJUÍ), Ijuí (RS), Brasil e da Graduação em Direito da Universidade do Vale do Rio dos Sinos (UNISINOS), São Leopoldo (RS), Brasil.
}

** Doutor em Direito Público pela Universidade do Vale do Rio dos Sinos (UNISINOS); Docente do Progra-
\end{abstract}


KEY WORDS: Basic Rights; Statute of the Foreigner; Inclusion; National Security.

\section{AUTORITARISMO VS. REDEMOCRATIZACIÓN: DEL INMIGRANTE EN BRASIL}

RESUMEN: Este artículo analiza la evolución de la política de inmigración brasileña, centrándose en los reflejos de la doctrina de la seguridad nacional a la legislación brasileña. Se investigó, en este ámbito, qué características pueden ser atribuidas al (des)respecto a los derechos fundamentales de los extranjeros, siendo considerado el orden constitucional de 1988. Se averiguó que, pese el gran proceso en la semántica constitucional referente al significado de la dignidad humana, en el Estatuto del Extranjero brasileño se verifica una continuidad del prejuicio, de la discrecionalidad del Poder Ejecutivo, y del choque entre esta ley y los objetivos del Estado brasileño instituidos en la Constitución.

PALABRAS-CLAVE: Derechos fundamentales; Estatuto del Extranjero, Inclusión, Seguridad Nacional.

\section{INTRODUÇÃO}

Apesar do processo de redemocratização ter ocorrido, no Brasil, há três décadas, nota-se, nas comunicações estatais (leis, políticas, etc.) acerca da condição jurídica do imigrante no país, que evidenciam o descompasso entre autoritarismo e democracia. Dá-se esta ocorrência em razão, principalmente, da reiteração da retórica da segurança nacional e da defesa dos interesses nacionais neste âmbito.

A análise dessas contraposições assume, assim, relevância jurídica fundamental. Ora, se a ordem constitucional a partir de 1988 comunica a intenção de democratizar a sociedade, isto significa incluir (e não discriminar, portanto) o estrangeiro de situação regular no país com tratamento isonômico àquele destinado ao brasileiro em vários âmbitos públicos sensíveis. A intensificação dos movimentos migratórios na sociedade global - provocada por várias razões diversas (sendo exemplos mais significativos os exemplos dos conflitos e crises em outros países; dos avanços tecnológicos no que tange aos transportes e à informação) - e a mudança de paradigma do significado da cidadania após o advento da globalização, incluir o imigrante nos sistemas comunicativos (Política e Direito, principalmente) significa efetivar seus direitos no sentido de uma cidadania cosmopolita. 
Este trabalho busca investigar a evolução da política legislativa recente do tratamento dos direitos dos estrangeiros no Brasil, mediante o estudo das repercussões da temática da segurança nacional na legislação brasileira atinente à política migratória nacional. Atém-se, assim, à análise da evolução histórica da legislação brasileira que trata do imigrante, desde o início do século XX até a mais atual proposta legislativa para tratamento da matéria, o Projeto de Lei da Câmara $\mathrm{n}^{\mathrm{o}}$ $6.556 / 2009$.

O problema de pesquisa que lhe serviu de diretriz pode ser descrito sinteticamente da seguinte forma: que características se pode atribuir ao (des) respeito aos direitos fundamentais dos estrangeiros no Brasil, considerando-se os dispositivos da Constituição Federal de 1988 atinentes à matéria, bem como a legislação acerca da matéria?

Propõe-se a hipótese que, mesmo com os grandes avanços atinentes ao respeito dos direitos fundamentais no texto constitucional brasileiro de 1988 o qual evoca, como fundamento do Estado, a dignidade da pessoa humana (art. $1^{\mathrm{o}}$, III); objetiva a promoção do bem de todos a despeito de qualquer forma de discriminação (inclusive a de origem) (art. $3^{\circ}$, IV); e que se rege, no plano das relações internacionais, pela prevalência dos direitos humanos $\left(\operatorname{art.} 4^{\mathrm{O}}, \mathrm{II}\right)^{1}-$, verifica-se, no plano legislativo de regulação da condição jurídica do estrangeiro no Brasil, a continuidade de um discurso totalmente discriminatório, de subjugação à discricionariedade do Poder Executivo e em descompasso com o que o próprio Estado se propõe constitucionalmente.

Frente a essa situação, é notável a necessidade de uma reviravolta pragmática em relação aos Direitos Humanos dentro da ordem jurídica nacional. A adoção de uma perspectiva de observação dos direitos humanos não apenas como formadores de um discurso de obliteração ao intervencionismo estatal, mas sim, como componente do programa do sistema do Direito no Brasil é possível. Este componente, que objetiva, mormente, a inclusão da pessoa humana nas comunicações jurídicas e políticas, é diretriz normativa necessária para a possibilidade argumentativa de respeito aos direitos dos imigrantes no Brasil.

Demonstra-se, no primeiro momento deste texto, a partir do modo como o Brasil historicamente administra o tema da imigração, a influência dos discursos de segurança nacional na seleção utilitarista de mão de obra estrangeira no Estatuto do

${ }^{1}$ BRASIL. Constituição (1988). Constituição da República Federativa do Brasil de 1988. Disponível em: < http:// www.planalto.gov.br/ccivil_03/constituicao/constituicao.htm >. Acesso em: 14 ago. 2014. 
Estrangeiro (Lei $n^{0}$ 6.815/80) e as reminiscências desse ideário no Projeto de Lei da Câmara nº 6.556/2009.

Já no seu segundo momento se realiza uma análise do referencial da Teoria dos Sistemas Autopoiéticos no que tange à definição da ideia de Constituição como acoplamento estrutural entre os sistemas sociais comunicativos da Política e do Direito. Apresenta-se que a apresentação da Constituição de tal maneira permite visualizar a diferenciação funcional da sociedade moderna como sendo demonstração de menores possibilidades de violação de direitos pela política.

Por fim, buscam-se definições pragmáticas das ideias de Direitos Humanos e Fundamentais como modos de acoplamento entre Direito e Política, a fim de se propor a possibilidade de maior respeito aos Direitos Humanos do estrangeiro no Brasil - mesmo que a legislação ainda vigorante, quando analisado o texto constitucional em consonância para com a matéria, revele um descompasso autoritário e discricionário.

\section{SEGURANÇA NACIONAL E UTILITARISMO COMO SUBTERFÚGIOS PARA O DESAMPARO DO ESTRANGEIRO}

Evidencia-se um histórico de continuidade de práticas autoritárias e antidemocráticas no Brasil na análise das políticas migratórias que o país tem adotado. Isto se dá porque essas políticas têm sido marcadas por um caráter que concilia duas lógicas diversas: de uma banda, verifica-se um discurso acolhedor; de outra, práticas e medidas legislativas altamente restritivas e seletivas aos direitos dos imigrantes.

Desde o desembarque, no século XIX, das primeiras levas de imigrantes europeus no Brasil, exigia-se dos estrangeiros a conformação à imagem de "trabalhador honesto" e qualificado, o que significava, invariavelmente, o afastamento das questões políticas nacionais. É nesse contexto que surge a chamada "Lei dos Indesejáveis", criada em 1907, objetivando a expulsão de estrangeiros acusados de exploração sexual, vagabundagem, vigarice, delitos patrimoniais e, principalmente, anarquismo, "articulado como ameaça principal" mas que, às vezes, "aparecia combinado a outras ameaças mais difusas, que se opunham 'à segurança nacional e à ordem pública'”. Nesse contexto, evidenciavam-se 
As referências a caftens, ladrões, mendigos e bandidos, juntamente com os anarquistas, reuniam diversas formas de não trabalho (assalariado) sob uma mesma denominação - indesejáveis - que ganhava, então, sentidos morais e políticos. ${ }^{2}$

Aliás, era marcante, nos debates parlamentares da época, "era evidente o temor provocado pela figura do anarquista estrangeiro, que corporificava o 'outro' da nação, devendo ser extirpado". ${ }^{3}$

Esta legislação pode ser considerada como uma resposta repressora aos então crescentes movimentos operários. Os processos de expulsão de estrangeiros no período entre 1907 e 1930, conforme fontes históricas localizadas no Arquivo Nacional, demonstram as arbitrariedades cometidas contra muitos imigrantes, expulsos "por desemprego ou por participar em movimentos sindicais, sem qualquer direito à defesa", ${ }^{4}$ demonstrando-se, claramente, a mixofobia. ${ }^{5}$

Na década de 1930 também se observam no país medidas de restrição à entrada de imigrantes, então como reflexo da crise econômica mundial vivenciada em 1929, que repercutiu na cultura cafeeira no Brasil. Tais restrições ocasionaram a fixação de cotas de imigração nas Constituições de $1934^{6}$ e de $1937 .^{7}$ Isto também se deu em razão da preocupação dos governantes da época com a instabilidade interna que adviria da formação de polos de imigrantes, o que eventualmente significaria o surgimento de uma economia, de uma cultura e de uma política paralelas (e até mesmo opostas) às do governo central. ${ }^{8}$ Em razão disso, o primeiro "Estatuto do Estrangeiro" a vigorar no país (Decreto-Lei $n^{\circ} 406$, de 1938) determinava que "nenhum núcleo colonial, centro agrícola, ou colônia fosse constituído por estrangeiros de uma só nacionalidade".

$\overline{2}$ GORDO, Adolpho. A expulsão de estrangeiros. São Paulo: Espíndola, 1918.

3 SCHETTINI, Cristiana. Exploração, gênero e circuitos sul-americanos nos processos de expulsão de estrangeiros (1907-1920). Tempo [online], v. 18, n. 33, 2012, p. 56.

4 SILVA, Érica Sarmiento da. A "não democracia" dos excluídos: alguns pontos da política imigratória brasileira. Logos 27: mídia e democracia. Ano 14, 2007, p. 144.

5 BAUMAN, Zygmunt. Confiança e medo na cidade. Rio de Janeiro: Jorge Zahar, 2009.

6 BRASIL. Constituição (1934). Constituição da República dos Estados Unidos do Brasil de 1934. Disponível em: < http://www.planalto.gov.br/ccivil_03/constituicao/constituica034.htm>. Acesso em: 14 ago. 2014.

7 O art. 121 da Constituição de 1934 e o art. 151 da Constituição de 1937 estabeleceram uma cota de no máximo $2 \%$ sobre o número total dos respectivos nacionais fixados no Brasil durante os últimos cinquenta anos, aplicada por nacionalidade (BRASIL. Constituição (1937). Constituição dos Estados Unidos do Brasil de 1937. Disponível em: < http://www.planalto.gov.br/ccivil_03/constituicao/constituica037.htm > . Acesso em: 14 ago. 2014).

8 LOPES, Cristiane Maria Sbalqueiro. Direito de imigração: o estatuto do estrangeiro em uma perspectiva de direitos humanos. Porto Alegre: Nuria Fabris, 2009.

9 BRASIL. Decreto-Lei $\mathrm{n}^{\mathrm{O}}$ 406, de 04 de maio de 1938. Dispõe sobre a entrada de estrangeiros no território nacional. Disponível em: <http://www2.camara.leg.br/legin/fed/declei/1930-1939/decreto-lei-406-4-maio1938-348724-publicacaooriginal-1-pe.html > . Acesso em: 14 ago. 2014. 
Com o advento da Segunda Guerra Mundial, os fluxos migratórios em direção ao Brasil se interromperam de modo quase completo, o que se verifica em razão das políticas restritivas de imigração adotadas na época, como, por exemplo, o Decreto-Lei $n^{0} 3.175$, de $1941,{ }^{10}$ que suspendia a concessão de vistos temporários ou permanentes para estrangeiros (salvo em algumas hipóteses excepcionais expressamente previstas em tal instrumento normativo). Ademais, na Constituição de $1946^{11}$ o caráter restritivo e seletivo da política migratória também é gritante: o art. 162 do referido texto dispunha que a seleção, a entrada, a distribuição e a fixação de imigrantes seriam sujeitas, na forma da lei, às exigências do interesse nacional.

$\mathrm{Na}$ segunda metade do século XX, a imigração para o Brasil continuou incipiente, o que está "associado à praticamente inexistente emigração, [e que] indicava que até meados dos anos 1980 o Brasil, em termos demográficos, poderia ser considerado um país fechado à migração". ${ }^{12}$ Efetivamente, a partir da década de 1970, quando o país estava em franco processo de industrialização, com uma população concentrada nos centros urbanos, o interesse em atrair imigrantes decaiu muito significativamente. Além disso, a introdução da já referida doutrina da segurança nacional pelo regime militar de então motivou uma legislação bastante restritiva dos direitos dos estrangeiros no país:

O nacionalismo se convertia em anticomunismo e o país se protegia das influências internacionais. Aos estrangeiros eram impostas várias proibições na área política, de associativismo e de atuação em áreas consideradas estratégicas". ${ }^{13}$

Isso justifica, em parte, a desconsideração da imigração pelo texto constitucional de 1967, o que revela uma clara opção pela soberania estatal em oposição à autodeterminação pessoal, bastante clara na época da ditadura militar.

Atualmente, ao se consolidar como uma das economias mundiais mais importantes, o Brasil volta a atrair cada vez mais a atenção dos imigrantes. "No período 2008 a 2011 o número de estrangeiros que obtiveram visto de trabalho/ residência no Brasil aumentou em 60,0\%, passando de 43.993 solicitações atendidas em 2008 para 70.524, em 2011". ${ }^{14}$

\footnotetext{
${ }^{10}$ Id. Decreto-Lei $n^{0} 3.175$, de 1941. Código Penal. Disponível em: < http://www.planalto.gov.br/ccivil_03/decreto-lei/del3689.htm >. Acesso em: 14 ago. 2014.

${ }^{11}$ Id. Constituição (1946). Constituição dos Estados Unidos do Brasil de 1946. Disponível em: < http://www. planalto.gov.br/ccivil_03/constituicao/constituicao46.htm>. Acesso em: 14 ago. 2014.

${ }^{12}$ PATARRA, Neide Lopes. O Brasil: país de imigração? E-metropolis: Revista eletrônica de estudos urbanos e regionais, Rio de Janeiro, 2012, p. 10.

${ }^{13}$ LOPES, Cristiane Maria Sbalqueiro. Direito de imigração: o estatuto do estrangeiro em uma perspectiva de direitos humanos. Porto Alegre: Nuria Fabris Editora, 2009, p. 169.

${ }^{14}$ PATARRA, Neide Lopes. O Brasil: país de imigração? E-metropolis: Revista eletrônica de estudos urbanos e regionais, Rio de Janeiro, 2012.
} 
Diante do anacronismo do Estatuto do Estrangeiro ${ }^{15}$ - resquício do período em que o país viveu sob regime ditatorial - o Brasil tem tratado a imigração de forma discricionária e truculenta, particularmente na atuação da Polícia Federal, órgão responsável pelo atendimento dos imigrantes para o processamento de sua documentação brasileira.

Os critérios para a concessão dos pedidos de visto e de residência não são previstos de forma apropriada no Estatuto ou em qualquer outra regra, o que acaba por abrir margem a avaliações bastante subjetivas por parte dos agentes administrativos. A propósito, o art. $7^{\circ}$ do Estatuto - demonstrando claramente sua herança ditatorial - dispõe, em seu inciso II, que a entrada do estrangeiro pode ser negada caso ele seja considerado nocivo à "ordem pública" ou aos "interesses nacionais". No mesmo sentido, os arts. $1^{\circ}, 2^{\circ}$ e $3^{\circ}$ do Estatuto utilizam os conceitos indeterminados de "interesse nacional" e "segurança nacional", revelando, assim, a "tônica" da legislação.

A relação estabelecida pela legislação brasileira sobre imigração entre a entrada de estrangeiros no país e a "segurança nacional" evidencia a compreensão dos processos migratórios enquanto "ameaça" ou "invasão", conceitos típicos de uma legislação de exceção. No entanto, esses conceitos foram superados pelo advento da Constituição Federal de 1988, que prioriza a proteção aos direitos humanos em detrimento dos vagos bens jurídicos "interesse nacional" e "ordem pública".

No que se refere à concessão de vistos, $\mathrm{o}$ art. 26 do Estatuto em vigor dispõe que o visto concedido pela autoridade consular configura mera "expectativa de direito", de modo que e a entrada, estada ou registro do imigrante pode ser obstada nas hipóteses previstas no seu art. $7^{\circ}$ - dentre as quais se situa a já mencionada consideração da eventual nocividade do imigrante à "ordem pública" ou aos "interesses nacionais" - bem como quando se julgar sobre "a inconveniência de sua presença no território nacional, a critério do Ministério da Justiça". ${ }^{16}$

Também é notável que, apesar de a Constituição Federal de 1988 dispor, em seu art. $5^{\circ}{ }^{17}$ acerca da igualdade de todos perante a lei, sem distinção de qualquer natureza, razão pela qual são garantidos tanto aos brasileiros, quanto aos estrangeiros residentes no País, uma série de direitos fundamentais, o Estatuto do

\footnotetext{
$\overline{{ }^{15} \text { BRASIL. Lei } \mathrm{n}^{\mathrm{0}} 6.815}$, de 19 de agosto de 1980. Define a situação jurídica do estrangeiro no Brasil, cria o Conselho Nacional de Imigração. Disponível em: < http://www.planalto.gov.br/ccivil_03/Leis/L6815compilado. $\mathrm{htm}>$. Acesso em: 12 fev. 2014.

${ }^{16}$ BRASIL. Lei $\mathrm{n}^{\circ}$ 6.815, de 19 de agosto de 1980. Define a situação jurídica do estrangeiro no Brasil, cria o Conselho Nacional de Imigração. Disponível em: < http://www.planalto.gov.br/ccivil_03/Leis/L6815compilado. htm > . Acesso em: 12 fev. 2014.

17 Id. Constituição (1988). Constituição da República Federativa do Brasil de 1988. Disponível em: < http:// www.planalto.gov.br/ccivil_03/constituicao/constituicao.htm>. Acesso em: 14 ago. 2014.
} 
Estrangeiro ${ }^{18}$ ainda prevê restrições a direitos dos imigrantes. $\mathrm{O}$ artigo 106, inciso VII, desta última lei prevê, por exemplo, vedação ao estrangeiro de "participar da administração ou representação de sindicato ou associação profissional, bem como de entidade fiscalizadora do exercício de profissão regulamentada". Ademais, o art. 107 do Estatuto proíbe que o estrangeiro admitido no território nacional exerça atividade política ou que se "imiscua" - e a utilização do verbo imiscuir denota a consideração do estrangeiro enquanto um "intruso" pelo legislador - direta ou indiretamente nos negócios públicos do Brasil.

Vê-se, dos dispositivos citados, que os termos empregados pelo legislador conferem ampla margem de discricionariedade para o julgamento subjetivo dos agentes públicos responsáveis pela concessão dos vistos. Tal subjetividade interpretativa dos dispositivos legais amparados em conceitos indeterminados gera uma grande insegurança jurídica para os imigrantes, que ficam à mercê de avaliações pessoais de agentes da Polícia Federal, órgão cuja lógica de funcionamento é a de investigação e combate à criminalidade.

O Projeto de Lei $\mathrm{n}^{\mathrm{0}} 5.655 / 2009,{ }^{19}$ em tramitação na Câmara dos Deputados e que visa a substituir o Estatuto do Estrangeiro, demonstra estar assentado sobre o mesmo paradigma orientador do Estatuto de 1980. Na verdade, o projeto em questão representa apenas uma espécie de atualização do antigo Estatuto: mesmo que afirme o respeito aos direitos humanos (arts. $2^{\circ}$ e $3^{\circ}$ ), em seu texto predominam dispositivos que demonstram privilegiar o primado do interesse nacional.

Isso justifica a permanência da proibição constante no art. 66, II, do Projeto de Lei, segundo o qual "não se concederá visto ou residência ou não se permitirá a entrada no País do estrangeiro" que for considerado "nocivo ao interesse nacional". Por seu turno, o art. 67 do Projeto revigora a mera "expectativa de direito" a que se refere o art. 26 do Estatuto ora vigente, quando dispõe que "a concessão de visto e a autorização de residência configuram mera expectativa de direito, podendo a entrada, a estada ou o registro do estrangeiro ser obstado nos termos desta Lei". ${ }^{20}$

18 BRASIL, 1980, op. cit.

19 Id. Poder Executivo. Projeto de Lei ${ }^{0}$ 5.655/2009. Dispõe sobre o ingresso, permanência e saída de estrangeiros no território nacional, o instituto da naturalização, as medidas compulsórias, transforma o Conselho Nacional de Imigração em Conselho Nacional de Migração, define infrações e dá outras providências. Disponível em: < http://www.camara.gov.br/proposicoesWeb/prop_mostrarintegra;jsessionid=91FEC9DE2FA2F83824F177AC481130EE.proposicoesWeb1?codteor $=674695 \&$ filename $=\mathrm{PL}+5655 / 2009>$. Acesso em: 25 mar. 2014.

20 BRASIL. Poder Executivo. Projeto de Lei no 5.655/2009. Dispõe sobre o ingresso, permanência e saída de estrangeiros no território nacional, o instituto da naturalização, as medidas compulsórias, transforma o Conselho Nacional de Imigração em Conselho Nacional de Migração, define infrações e dá outras providências. Disponível em: <http://www.camara.gov.br/proposicoesWeb/prop_mostrarintegra;jsessionid=91FEC9DE2FA2F83824F177AC481130EE.proposicoesWeb1 codteor $=674695 \&$ filename $=\mathrm{PL}+5655 / 2009>$. Acesso em: 25 mar. 2014. 
Os procedimentos administrativos previstos na redação do Projeto permanecem bastante burocratizados, sendo até mesmo verificados alguns retrocessos, como o aumento do tempo necessário ao pedido de naturalização, que passa de quatro anos (art. 112, III, Lei ${ }^{\circ}$ 6.815/1980) para dez (art. 87, III). É de se ressaltar, aliás, que numa disposição que beira o absurdo, o art. 97 do Projeto preconiza que "o atendimento das condições previstas nesta Lei não assegura ao estrangeiro o direito à naturalização", o que significa dizer que, mais uma vez, o alien fica à mercê da discricionariedade e da subjetividade do Poder Executivo.

A discriminação do estrangeiro também é demonstrada no art. $4^{\circ}$ do Projeto, ${ }^{21}$ que prevê que a política imigratória objetivará, primordialmente, a admissão de mão de obra especializada adequada à economia nacional. Ou seja, a imigração é interpretada, legislativamente, de modo utilitarista, colocando o imigrante na condição de fator de produção. Disto se infere que a estadia autorizada do imigrante é sempre inteiramente sujeita ao trabalho, "única razão de ser que lhe é reconhecida", se podendo afirmar que "foi o trabalho que fez 'nascer' o imigrante, que o fez existir, e é ele, quando termina, que faz 'morrer' o imigrante, que decreta sua negação ou que o empurra para o não-ser". ${ }^{22}$

Outro ponto do projeto de lei que merece ser destacado é a persistência, em seu art. $8^{\circ}$, da restrição aos direitos políticos dos imigrantes..$^{23}$ Esquece-se, aqui, que estes direitos já fazem parte do acervo de direitos dos estrangeiros regularmente presentes na maioria dos países democráticos. Na América Latina, as Constituições da Bolívia ${ }^{24}$ e do Paraguai ${ }^{25}$ admitem que o estrangeiro vote nas eleições municipais. No Uruguai ${ }^{26} \mathrm{o}$ direito de voto é conferido ao estrangeiro que resida há pelo menos

${ }^{21}$ Ibid.

${ }^{22}$ SAYAD, Abdelmalek. A imigração ou os paradoxos da alteridade. Trad. Cristina Murachco. São Paulo: Edusp, 1998 , p. 55.

${ }^{23}$ BRASIL, 2009, op. cit.

${ }^{24}$ Dispõe o art. 220 da Constituição da Bolívia: "Art. 220. Capacidad. I. Son electores todos los bolivianos mayores de deiciocho años de edad, cualquiera sea su grado de instrucción y ocupación, sin más requisito que su inscripción obligatoria en el Registro Electoral. II. En las elecciones municipales votarán los ciudadanos extranjeros en las condiciones que establezca la ley" (BOLÍVIA. Constituição (2009). Constitución del Estado Plurinacional de Bolivia de 2009. Disponível em: < http://bolivia.justia.com/nacionales/nueva-constitucion -politica-del-estado/segunda-parte/titulo-v/capitulo-segundo/seccion-i/\# articulo-220 > Acesso em: 14 ago. 2014).

${ }^{25}$ Art. 120 "los extranjeros con radicación definitiva tendrán los mismos derechos en las elecciones municipales" (PARAGUAI. Constituição (1992). Constitución de la República del Paraguay de 1992. Disponível em: < http:// www.constitution.org/cons/paraguay.htm > . Acesso em: 14 ago. 2014).

${ }^{26}$ Nos termos do disposto no art. 78 da Constituição do Uruguai (URUGUAI. Constituição (1997). Constitución de la República Oriental del Uruguay de 1997. Disponível em: < http://www.constitution.org/cons/paraguay. htm >. Acesso em: 14 ago. 2014). 
15 anos no país. A Constituição Chilena ${ }^{27}$ estabelece que a lei poderá estender o direito de voto aos estrangeiros residentes há mais de 5 anos no país, ressalvando-se apenas a sua não obrigatoriedade. ${ }^{28}$

No caso do projeto de lei brasileiro em discussão, as limitações não se restringem ao direito ao sufrágio. $\mathrm{O}$ art. $7^{\circ}$ do Projeto ${ }^{29}$ estabelece outras várias vedações, dentre as quais: a) ser proprietário de empresa jornalística e de radiodifusão sonora e de sons e imagens; b) ser responsável pelo conteúdo editorial e atividades de seleção e direção da programação veiculada em qualquer meio de comunicação social; c) ser proprietário ou explorador de aeronave brasileira; d) adquirir, em nome próprio ou de terceiros, terras em região de fronteira; e) ser proprietário, sócio ou empregado de empresa de segurança privada e de formação de vigilantes. É flagrante, em todas essas proibições, a visão do estrangeiro como fonte potencial de riscos pelo legislador brasileiro.

Esta consideração do migrante enquanto "inimigo potencial" também se extrai da análise do art. $6^{\circ}$ do Projeto de Lei, que prevê que o estrangeiro "deverá comprovar sua estada regular no território nacional sempre que exigido por autoridade policial ou seu agente", o que significa a permanência de uma forma policialesca de tratamento da questão e que representa a criação de uma injustificável quebra do princípio da igualdade previsto no art. $5^{\circ}$ da Constituição Federal.

Estes breves exemplos de tratamento discriminatório perpetrado pelo Projeto de Lei $\mathrm{n}^{0}$ 5.655/2009 permitem evidenciar que a imigração no Brasil segue sendo compreendida enquanto "problema", o que legitima que seja gerida em nível de "segurança", fato que, por sua vez, impõe restrições injustificadas a direitos e garantias fundamentais dos migrantes. Relacionada a isso está uma compreensão

${ }^{27}$ Art. 14 "los extranjeros avecindados en Chile por más de cinco años, y que cumplan con los requisitos señalados en el inciso primero del artículo 13, podrán ejercer el derecho de sufragio en los casos y formas que determine la ley." Por sua vez, o art. 15 determina que "en las votaciones populares, el sufrágio será personal, igualitario y secreto. Para los ciudadanos será, además, obligatorio” (CHILE. Constituição (1980). Constitución política de la República de Chile de 1980. Disponível em: < http://www.camara.cl/camara/media/docs/constitucion_politica.pdf > . Acesso em: 14 ago. 2014).

${ }^{28}$ Há, no Brasil, Propostas de Emenda Constitucional que discutem a possibilidade de voto para estrangeiros, dentre elas cabendo destaque à PEC 119/2011, de autoria do deputado Roberto Freire, que permite o voto de estrangeiros em eleições no Brasil, limitando-o aos pleitos municipais (FREIRE, Roberto. Proposta de Emenda à Constituição $n^{\circ}$ 119/2011. Disponível em: <http://www.camara.gov.br/proposicoesWeb/prop_mostrarintegra? codteor $=947592 \&$ filename $=P E C+119 / 2011>$. Acesso em: 14 ago. 2014).

${ }^{29}$ BRASIL. Poder Executivo. Projeto de Lei $n^{0} 5.655 / 2009$. Dispõe sobre o ingresso, permanência e saída de estrangeiros no território nacional, o instituto da naturalização, as medidas compulsórias, transforma o Conselho Nacional de Imigração em Conselho Nacional de Migração, define infrações e dá outras providências. Disponível em: < http://www.camara.gov.br/proposicoesWeb/prop_mostrarintegra;jsessionid=91FEC9DE2FA2F83824F177AC481130EE.proposicoesWeb1?codteor $=674695$ \&filename $=\mathrm{PL}+5655 / 2009>$. Acesso em: 25 mar. 2014. 
coletiva do imigrante como sendo o oposto ao "natural" - uma vez que aceita abandonar o universo familiar (social, econômico, político, cultural, moral, etc.) ao qual pertence - e que, em virtude disso, se submente à vida em território estrangeira "com a condição de se convencer de que isso não passa de uma provação, passageira por definição, uma provação que comporta em si mesma sua própria resolução". ${ }^{30}$

\section{CONSTITUIÇÃO E TEORIA DOS SISTEMAS AUTOPOIÉTICOS}

Dada a importância dos direitos constitucionalmente postos para os objetivos do presente trabalho, é necessário realizar-se não apenas uma análise sintática dos seus dispositivos em relação a outras normas (tais como aquelas contidas no Estatuto do Estrangeiro). Faz-se imprescindível, isto sim, analisar qual é a sua importância dentro dos processos sociais, bem como o local que ocupa teoricamente. Eis o motivo pelo qual se passa a discorrer acerca da Constituição dentro de uma teoria social (a dos sistemas autopoiéticos).

Observa-se nas Constituições que o paradoxo da diferença entre Direito e Política passa a não mais ser resolvido pela hierarquia entre direito divino, natural e positivo (a qual servira ao Estado, quando das priscas eras da Modernidade, para a afirmação da sua soberania absoluta), mas sim, mediante a afirmação definitiva da positividade do Direito: "o Direito positivo bifurca-se em direito intangível e direito disponível". ${ }^{31}$ Assim, tanto para o subsistema parcial comunicativo político quanto para o jurídico, a Constituição se torna uma nova modalidade de diferenciação nas operações internas do sistema, entre a auto e a heterorreferência. ${ }^{32}$

Juridicamente, a Constituição seria o substituto funcional do Direito Natural, eis que constitui seu instrumento de "positivação". Já do ponto de vista político, é o locus comunicativo em que o poder absoluto do monarca é substituído pelo reconhecimento dos direitos dos cidadãos como limitação para o exercício do poder. Assim, mediante ela se criam e limitam liberdades consentidas a ambos os sistemas. $\mathrm{E}$, com isto, surge a diferença entre direitos humanos e direitos fundamentais, sendo

\footnotetext{
${ }_{30}$ SAYAD, Abdelmalek. A imigração ou os paradoxos da alteridade. Trad. Cristina Murachco. São Paulo: Edusp, 1998 , p. 57.

31 LUHMANN, Niklas. Sistemas sociales: lineamientos para uma teoría general. Tradução para o espanhol de Silvia Pappe e Brunhilde Erker; Coordenação de Javier Torres Nafarrate. México: Allianza Editorial/Universidad Iberoamericana, 1991, p. 41.

32 LUHMANN, Niklas. La costituzione come acquisizione evolutiva. In: ZAGREBELSKY, Gustavo; PORTINARO, Pier Paolo; LUTHER, Jorg. Il Futuro dela Costituzione. Torino: Einaudi, 1996b.
} 
que, nos idos do séc. XVIII, estes segundos assumem o significado de "direitos de liberdade positivados em uma ordem jurídico-política concreta, isto é, em um determinado Estado", enquanto os direitos humanos se tornam direitos inerentes ao próprio poder advindo da condição de pessoa. ${ }^{33}$

Apresentam-se, na diferença entre direitos humanos e fundamentais, pois, dois critérios quando do advento da ideia moderna de Constituição: um territorial (direitos fundamentais seriam reconhecidos no interior de uma determinada ordem estatal); e um temporal - ao serem fundados constitucionalmente os direitos fundamentais na sua projeção para o futuro, apresenta-se a possibilidade de sua efetivação no presente. Em outras palavras: "decisões presentes [tornam-se passíveis de serem] tomadas com base naquelas expectativas futuras que, por sua vez, podem vir a não se realizarem".34

As Constituições, na modernidade, significaram a unidade da diferença (ainda que precária e artificialmente) entre os sistemas do Direito e da Política, representando o instrumental que impediu o fechamento da Política e do Direito em si próprios: um limita o outro, ao mesmo tempo em que ambos são livres para realizarem suas operações (até o limite do outro); contudo, cada um de ambos é autorreferente a operacionalmente fechado (apesar de cognitivamente aberto). ${ }^{35}$ Ao se fundamentalizarem nas Constituições, os Direitos Humanos adquirem significados diversos para o Direito e para a Política: enquanto para aquele os direitos tornados fundamentais são os pilares da própria Constituição, para este os direitos se traduzem em instrumentos políticos, "no duplo sentido de política instrumental - modificadora de situações - e de política simbólica - não modificadora de situações". ${ }^{6}$

Nas condições da sociedade moderna, entretanto, sendo os Direitos Humanos visualizados a partir dessa dupla perspectiva (fundamental, para o Direito; instrumental, para a Política), não se tornam capazes de integrar ambos os sistemas - e isto não apenas em decorrência do conflito igualdade/liberdade (ou soberania popular/direitos humanos): esta não convergência provém da própria diferenciação

${ }_{33}^{3}$ MAGALHÃES, Juliana Neuenschwander. O paradoxo dos direitos humanos. Revista da Faculdade de Direito UFPR, Curitiba, n. 47, p. 29-64, 2008, p. 41.

${ }^{34}$ Ibid., p. 42.

${ }^{35}$ Ibid., p. 43-44.

${ }^{36}$ LUHMANN, Niklas. El derecho de la sociedad. Tradução para o espanhol de Javier Torres Nafarrate, com colaboração de Brunhilde Erker, Silvia Pappe e Luis Felipe Segura. 2. ed. Cidade do México: Herder, Universidad Iberoamericana, 2005, p. 548, tradução nossa. Texto original: "[...] en el doble sentido de política instrumental - modificadora de situaciones - y de política simbólica - no modificadora de situaciones". 
funcional, que coloca a cada sistema a função de resolver diferentes problemáticas sociais (e os Direitos Humanos passam a ser interpretados de diferentes maneiras por cada um deles).

Mas a politização simbólica dos Direitos Humanos não pode ser atribuída à não diferenciação funcional, unicamente. O Direito, mediante a constitucionalização, possui capacidade de simbolização da Política - e, em razão dessa capacidade (negativa), duas questões emergem:

a) a instrumentalização da Constituição em desfavor da realização dos projetos apresentados constitucionalmente não é um privilégio dos países tidos como "subdesenvolvidos";

b) a possibilidade de instrumentalização dos Direitos Humanos com vistas ao seu não cumprimento é um fenômeno decorrente justamente da diferenciação funcional. Às situações de não efetivação dos Direitos Humanos deve se somar também, portanto, a corrupção dos sistemas (que pode ocorrer tanto no "Primeiro Mundo" quanto no "Terceiro Mundo"), "quando um sistema se recusa a funcionar com base em seu próprio código, tomando decisões referidas aos códigos de outros sistemas" ${ }^{\prime 37}$ (e isto inclui as mais variadas situações, desde a venda de decisões judiciais até a fundamentação de decisões no caráter "justo", e não jurídico, de algo).

Em razão da diferenciação Direito/Política, no que tange aos Direitos Humanos, novamente emerge o caráter paradoxal destes - sendo que, para que sobrevivam às Constituições e à "crise da soberania", novos fundamentos devem ser encontrados para eles: tanto a ideia de direitos naturais quanto a de fundamentalização mediante a positivação constitucional quedam-se insuficientes no atual contexto (mundializado ou, conforme a linguagem mais comumente utilizada, "globalizado"), tornando-se frequente falar-se em um cosmopolitismo embasado na ideia de Direitos Humanos. Exsurge, assim, o discurso da desvinculação das referências territoriais, jurídicas e políticas estatais, vislumbrando-se que a expectativa ao redor dos Direitos Humanos é de que eles

${ }^{37}$ MAGALHÃES, Juliana Neuenschwander. O paradoxo dos direitos humanos. Revista da Faculdade de Direito UFPR, Curitiba, n. 47, p. 29-64, 2008, p. 46. 
transcendam as fronteiras dos Estados, do poder e do direito estabelecido. Da mesma forma, reacendem-se velhas esperanças de que, pela via dos direitos humanos, a sociedade moderna possa encontrar um caminho para sua integração. Ou seja, que não apenas direito e política, mas também os outros sistemas sociais, como a economia ou a educação, possam se deixar regular pelo primado dos direitos humanos. ${ }^{38}$

É particularmente em razão disto que é possível afirmar que os Direitos Humanos, ao ser esvaziada a possibilidade de serem encarados como realidades (ontológicas), são ficções capazes de produzir realidades - ou seja, embora sejam paradoxais em sua natureza, são capazes de se desenvolverem operativamente. ${ }^{39}$ A realidade mostra, assim, que mais relevante do que buscar os fundamentos dos Direitos Humanos ou identificar quais são as promessas não cumpridas feitas em seu nome, deve-se observar seriamente o que é efetivamente produzido conforme sua lógica.

No que tange à temática dos direitos dos estrangeiros no Brasil, portanto, pode-se notar que há impasses e contradições tanto no interior de cada sistema (político e jurídico) quanto comparando-se as comunicações de um em relação ao outro. Há um descompasso entre as comunicações de sentido jurídico que excluem o imigrante do próprio sistema:

a) Enquanto na ordem internacional se trata de direitos humanos em uma ordem global, cujos titulares são pessoas, e não mais a cidadãos propriamente ditos, na ordem interna do Brasil os direitos fundamentais dos estrangeiros, mesmo estando constitucionalmente positivados (eis que são da titularidade de todos) encontra óbices na legislação;

b) Politicamente, o programa constitucional, instrumento para as comunicações políticas, é utilizado no sentido de dar a continuidade a uma cultura de inclusão e exclusão valorativas. Em tal cultura política, incluem-se apenas os imigrantes considerados economicamente úteis - mas mesmo estes estão à deriva da fundamentalidade dos direitos, dado que sua condição de regularidade obedece apenas a critérios discricionários políticos.

\footnotetext{
38 MAGALHÃES, Juliana Neuenschwander. O paradoxo dos direitos humanos. Revista da Faculdade de Direito UFPR, Curitiba, n. 47, p. 29-64, 2008, p. 46.

39 Ibid., p. 47.
} 
É necessário analisar, portanto, a relação entre direitos humanos, fundamentais e legislativamente positivados (ou seja, instrumentalizados politicamente) para além das relações sintáticas: pragmaticamente se deve observar os modos pelos quais as possibilidades de inclusão dos imigrantes no sistema podem se dar. Eis a motivação do próximo trecho deste trabalho: demonstrar que, sistemicamente falando, há como se observar os direitos fundamentais como instrumentos (políticos e jurídicos) para a inclusão de qualquer forma de excluídos (dentre eles, os imigrantes).

\section{PRAGMÁTICA INCLUDENTE DOS DIREITOS HUMANOS E FUNDAMENTAIS}

Queda-se extremamente dificultoso para o Direito (mormente no que tange aos Direitos Humanos) observar as comunicaçóes relacionadas àquilo que possa significar o humano. Estando inscritos no sistema jurídico, os Direitos Humanos são estabelecidos como expectativas normativas, caracterizadas pela não assimilação da decepção - diferentemente das expectativas cognitivas sobre as quais o sistema da Ciência se funda, expectativas estas cuja característica seria a tendência de aptidão à assimilação de desapontamentos..$^{40}$

Ao se trazer a observação dos Direitos Humanos e fundamentais como sendo constitutivos de um manancial de significação para a práxis dos sistemas internos, estatais, do Direito; ao se observar decisões tomadas e teorias desenvolvidas por outros sistemas do Direito, oriundos de outras ordens estatais como modelo a ser reavaliado no diálogo entre ordens, e não como mero transplante de material alienígena; ao se reconsiderar a própria policontexturalidade e a hipercomplexidade normativas como características das possibilidades de comunicação, em que se podem visualizar catálises provocativo-transformativas do sentido jurídico das mais variadas ordens; estar-se-á diante de uma forma de observação de um Direito complexo para uma sociedade complexificada pelas transformações causadas no ambiente social pelos mais variados sistemas.

Seria mais coerente em relação ao atual estado de coisas, dessa forma, abandonar a ideia de fundamentação dos Direitos Humanos em uma semântica

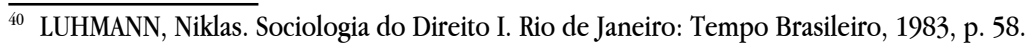


ultrapassada da moralidade, em prol daquilo que Luhmann ${ }^{41}$ denomina "danos da verdade": uma sociedade altamente complexa, no qual o caráter científico passa a influenciar cada vez mais âmbitos sociais (e inclusive o Direito), não pode deixar de atribuir importância ao aspecto cognitivo das comunicações que estabeleçam pretensas verdades (exceto, por óbvio, quando a possibilidade de falseabilidade de tais comunicações ainda esteja por demais presente).

Assim, tem-se que "é preciso verificar o humano (e seus direitos) no presente, e não em uma semântica anterior" ${ }^{\star 22}$ (da qual seria exemplo paradigmático a classificação da qualidade do ser humano de acordo com sua nacionalidade). Mais profícuo do que remontar a ideia de Constituição a uma moralização decorrente de uma tradição histórica correlata ao advento da modernidade apenas ("nascimento" do Estado-nação), é ter em sua ideia a possibilidade comunicativa de efetivação dos direitos que ela positiva mediante a identificação de sua semântica à pragmática nela contida, acoplando-a estruturalmente a outros sistemas sociais (Política, Economia, etc.).

A situação de constante presença dos riscos em todos os âmbitos sociais (inclusive o risco relacionado à entrada de estrangeiros com direitos reconhecidos no âmbito de outro Estado) torna compreensível o desespero por uma ética que inexiste de fato, ou por um conclame ético que pretensamente aponta para a necessidade de maior atenção aos riscos e perigos. A sociedade se sente carente de uma instância que a represente como um todo, capaz de dizer, apontar qual seria o comportamento eticamente correto e racional em situações arriscadas. Porém, a existência desta instância sequer é possível, pois a sociedade não pode pressupor uma representação da sociedade na sociedade (pois qualquer pretensão neste sentido estaria exposta à observação e à crítica). ${ }^{43}$

Ademais, não há uma unidade autopoiética que contenha todos os sistemas constitutivos humanos (psíquico, biológico e comunicativo) - mas isto não significa que o humano não exista: tal raciocínio apenas afasta a possibilidade de configuração

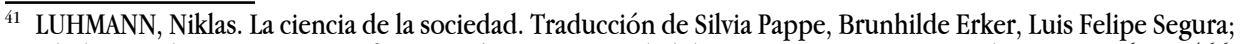
sob direção de Javier Torres Nafarrate. México: Universidad Iberoamericana; ITESO; Anthropos, 1996a, p. 466.

${ }^{42}$ SCHWARTZ, Germano. O humano e os humanos nos direitos humanos. Animais, Pacha Mama e altas tecnologias. In: SCHWARTZ, Germano (Org.). Juridicização das esferas e fragmentação do direito na sociedade contemporânea. Porto Alegre: Livraria do Advogado Editora, 2012, p. 223.

43 LUHMANN, Niklas. La ciencia de la sociedad. Traducción de Silvia Pappe, Brunhilde Erker, Luis Felipe Segura; sob direção de Javier Torres Nafarrate. México: Universidad Iberoamericana; ITESO; Anthropos, 1996a, p. 467468. 
absoluta de um antropocentrismo em nível de teoria sociológica. ${ }^{44}$ Com isto, tem-se que o essencial não é definir o que é o ser humano para os Direitos Humanos, mas sim, em conceber o sentido do humano na comunicação específica estabelecido pelo sistema do Direito - pois nenhum dos sistemas que se acoplam para constituir o humano o representa integralmente, sendo necessário conceber os três (corpo, psique, representação social) como importantes para a sua configuração.

O uso da expressão "Direitos Humanos" pretende fazer referência a uma noção surgida no contexto das revoluções liberais (Americana e Francesa, principalmente), e que se combinava ao conceito de cidadania, em sua origem, aos direitos dos membros de determinado Estado. Diferenciava-se da noção de "direitos do homem", pois esta se ligava aos direitos de todos aqueles que detivessem a condição humana, independentemente da pertença a uma comunidade política. ${ }^{45}$ Com o desenvolvimento das ideias acerca dos direitos, a ideia de liberdades negativas (em relação ao Estado) associada aos Direitos Humanos passa a ser desenvolvida também com as dimensões política (participar da escolha acerca do governo, em geral) e social (direitos, em stricto sensu, prestacionais a serem atendidos pelo Estado).

A partir da influência do constitucionalismo da Alemanha no primeiro quinto do século XX (mais especificamente com a promulgação da Constituição de Weimar, em 1919), passa a ser utilizada a expressão "direitos fundamentais" para se fazer referência aos direitos positivados e garantidos em Constituições estatais - sendo incluídos nesta categoria, porém, tanto os direitos de cidadania no sentido liberal quanto os direitos humanos ${ }^{46} \mathrm{~A}$ partir de então passa a ser proposta a distinção entre Direitos Humanos internacionalmente protegidos (afirmáveis, inclusive, contra os Estados) e os direitos fundamentais garantidos constitucionalmente pelos Estados. ${ }^{47}$ Mas seus conteúdos se entrecruzam nas categorias de direitos civis, políticos, sociais e novos direitos (transindividuais, principalmente). ${ }^{48}$

A abordagem luhmanniana acerca da matéria demonstra o esforço em se realizarem distinções entre ambas as categorias. Os direitos fundamentais

\footnotetext{
${ }^{44}$ LUHMANN, Niklas. La ciencia de la sociedad. Traducción de Silvia Pappe, Brunhilde Erker, Luis Felipe Segura; sob direção de Javier Torres Nafarrate. México: Universidad Iberoamericana; ITESO; Anthropos, 1996a, p. 226.

${ }^{45}$ NEVES, Marcelo. Transconstitucionalismo. São Paulo: Editora WMF Martins Fontes, 2009, p. 249-250.

${ }^{46}$ SCHMITT, Carl. Teoria de la constitucion. Madrid: Alianza, 1992, p. 164 e ss.

${ }^{47}$ DIMOULIS, Dimitri; MARTINS, Leonardo. Teoria Geral dos Direitos Fundamentais. São Paulo: Revista dos Tribunais, 2007, p. 40 e ss.

${ }^{48}$ NEVES, Marcelo. Transconstitucionalismo. São Paulo: WMF Martins Fontes, 2009, p. 250.
} 
(constitucionalmente positivados), assim, teriam a função de manter uma ordem diferenciada de comunicação (reagindo, então, ao "perigo da desdiferenciação"). ${ }^{49}$ Apesar de, em suas primeiras obras, ter desprezado a noção de direitos humanos por considerá-los "eternos", ${ }^{50}$ Luhmann passou, em suas obras posteriores, a dar ênfase ao fato de que "entre os mais importantes indicadores de um Sistema jurídico global está a crescente atenção dada à violação de direitos humanos" ${ }^{51}$

Já os direitos humanos guardariam relação direta para com o problema da exclusão - o que demonstraria que tais direitos seriam orientados para a inclusão do homem como pessoa nos sistemas sociais funcionais (especialmente no Direito).$^{52}$ Contudo, em Luhmann é notável uma semântica restritiva dos Direitos Humanos, nela incluindo apenas situações de violação extrema à dignidade humana na sociedade mundial, tais como o desaparecimento (assegurado pelo Estado) de pessoas, expulsões e deportações forçadas, prisão, tortura e mortes contrárias ao Direito (com proteção e conhecimento de órgãos estatais). ${ }^{53}$

A referida restrição não parece justificável para Neves, ${ }^{54}$ que considera que, para além das violações extremas aos direitos humanos avalizadas (de uma forma ou outra) pelo Estado, também deve ser entendida como violação

[...] a falta de condições mínimas de sobrevivência para grande parte da população na sociedade mundial de hoje, implicando como que uma exclusão social absoluta dos respectivos grupos humanos [...]. Trata-se do paradoxo da afirmação de expectativas normativas (contrafactuais) diante da própria prática que as contraria sistematicamente. A diferença reside no fato de que aqueles direitos humanos em sentido estrito, que se referem basicamente à proibição de ações violentas $[. .$.$] contra indivíduos ou grupos, são suscetíveis de institu-$ cionalização e, sobretudo, contam com perspectivas de positivação e implementação processual em escala mundial, [...] enquanto os chamados direitos humanos de terceira geração são fragilmente institucionalizados, e as perspectivas de sua positivação e implementação processual em extensão mundial são negativas.

49 LUHMANN, Niklas. Los derechos fundamentales como institución: aportación a la sociología política. Tradução para o espanhol de Javier Torres Nafarrate. México: Universidad Iberoamericana, 2010, p. 98-99.

50 LUHMANN, Niklas. Los derechos fundamentales como institución: aportación a la sociología política. Tradução para o espanhol de Javier Torres Nafarrate. México: Universidad Iberoamericana, 2010, p. 99.

${ }^{51}$ LUHMANN, Niklas. Law as a social system. Tradução para o inglês de Klaus A. Ziegert. New York: Oxford University Press, 2004, p. 482, tradução nossa. Texto original: "Among the most important indicators of a global legal system is the increasing attention paid to the violation of human rights".

52 LUHMANN, Niklas. Law as a social system. Tradução para o inglês de Klaus A. Ziegert. New York: Oxford University Press, 2004, p. 490.

53 LUHMANN, Niklas. Law as a social system. Tradução para o inglês de Klaus A. Ziegert. New York: Oxford University Press, 2004, p. 485-486.

${ }_{54}$ NEVES, Marcelo. Transconstitucionalismo. São Paulo: WMF Martins Fontes, 2009, p. 452. 
A interessante proposta do autor brasileiro é de que se definam primariamente os Direitos Humanos como sendo expectativas normativas destinadas à inclusão de todos os seres humanos na sociedade mundial - delineando-se como o acesso universal ao subsistema social do Direito. ${ }^{55}$ Este raciocínio acerca de tais direitos não se chocaria com a mais atual das concepções luhmannianas recémapresentadas, pois continua a ser sustentado que os Direitos Humanos reagem ao perigo da desdiferenciação - já que a manutenção de uma ordem diferenciada de comunicação na sociedade mundial e a orientação pela inclusão das pessoas nos sistemas funcionais (inclusive no Direito) são ideias intimamente ligadas. ${ }^{56} \mathrm{Em}$ outras palavras, quanto menor for a exclusão de pessoas dos sistemas sociais, mais realizada estará a diferenciação funcional dos sistemas parciais da sociedade (direito, Política, Economia, etc.)..$^{57}$

Nesta senda, tanto os Direitos Humanos quanto os fundamentais são respectivos à diferenciação da sociedade, que é ideia correlata, por sua vez, da busca pela inclusão da pessoa. A diferença entre as nomenclaturas (humanos ou fundamentais) residiria, assim, apenas no seu âmbito de pretensão de validade: enquanto os Direitos Humanos pretendem validade para o sistema jurídico mundial de múltiplos níveis (qualquer ordem jurídica da sociedade mundial, não apenas a ordem internacional), os fundamentais são válidos dentro de uma ordem constitucional determinada de um Estado. ${ }^{58}$

Gunther Teubner ${ }^{59}$ propôs uma distinção entre direitos fundamentais e humanos, a partir do conteúdo de cada um: enquanto os primeiros seriam orientados para a inclusão da pessoa, os segundos se refeririam à exclusão do homem da sociedade, dando-lhe garantias de integridade dos seus sistemas biológico e psíquico em relação à sociedade (e seus subsistemas) - pois afirma que os direitos humanos "devem ser entendidos como possuindo uma diferença semântica das liberdades comunicativas pessoais, nomeadamente como garantias intentadas da integridade de

\footnotetext{
55 NEVES, Marcelo. A força simbólica dos direitos humanos. In: Revista Eletrônica de Direito do Estado, n. 4. Salvador, Bahia, Brasil: out./dez. 2005.

${ }^{56}$ NEVES, Marcelo. Transconstitucionalismo. São Paulo: Editora WMF Martins Fontes, 2009, p. 253.

57 LUHMANN, Niklas. Law as a social system. Tradução para o inglês de Klaus A. Ziegert. New York: Oxford University Press, 2004, p. 488.

${ }^{58}$ NEVES, Marcelo. Transconstitucionalismo. São Paulo: WMF Martins Fontes, 2009, p. 253-254.

59 TEUBNER, Gunther. The anonymous matrix: Human Rights Violations by 'Private' Transnational Actors. Modern Law Review, v. 69, n. 3, p. 327-367, 2006, p. 338.
} 
corpo e mente" ${ }^{60}$ - e, nesta mesma senda, afirma o mesmo autor que "a questão dos direitos humanos no sentido mais estrito deve hoje ser vista como a periclitação da integridade de mente e corpo dos indivíduos por uma multiplicidade de processos comunicativos anônimos e, atualmente, globalizados" ${ }^{61}$

Apesar do valor da análise de Teubner recém-apresentada, parece ser menos intrincada e mais coerente a visão de Neves acerca do tema inclusão/exclusão, eis que, conforme afirma este segundo autor, "a garantia de integridade de corpos e mentes perante a sociedade, seus sistemas funcionais e as organizações só são possíveis se houver inclusão das respectivas pessoas" ${ }^{\prime 2}-$ ou, conforme afirmaria Luhmann, se a sociedade não tratar o homem como mera conjunção de psique e corpo, sem considerá-los dignos de personalidade, pois

Enquanto no âmbito da inclusão os seres humanos contam como pessoas, no da exclusão parecem importar unicamente como corpos. Os mecanismos simbióticos dos meios de comunicação perdem seu ordenamento específico. A violência física - a sexualidade, a satisfação elementar e impulsiva das necessidades - se liberam e se tornam imediatamente relevantes sem passar pela civilização das recursividades simbólicas; expectativas sociais mais pretensiosas já não podem se enlaçar. ${ }^{63}$

Analisa-se, desta feita, que a violação dos direitos humanos perpetradas pela política legislativa brasileira, mesmo após o advento de uma ordem constitucional muito mais igualitária e sem discriminação de origem, se configura como uma exclusão jurídica tanto de direitos de não-agressão da parte do Estado (direitos de primeira dimensão) quanto direitos prestacionais da parte deste (direitos de segunda dimensão). Ou seja: o próprio Estado, provocado por comunicações de ordem

\footnotetext{
${ }^{60}$ TEUBNER, Gunther. The anonymous matrix: Human Rights Violations by 'Private' Transnational Actors. Modern Law Review, v. 69, n. 3, p. 327-367, 2006, p. 338, tradução nossa. Texto original: "are to be understood as having a semantic difference from personal communicative freedoms, namely as intended guarantees of the integrity of mind and body".

${ }^{61}$ TEUBNER, Gunther. The anonymous matrix: Human Rights Violations by 'Private' Transnational Actors. Modern Law Review, v. 69, n. 3, p. 327-367, 2006, p. 341, tradução nossa. Texto original: "human rights question in the strictest sense must today be seen as endangerment of individuals' integrity of body and mind by a multiplicity of anonymous and today globalized communicative processes".

${ }^{62}$ NEVES, Marcelo. Transconstitucionalismo. São Paulo: Editora WMF Martins Fontes, 2009, p. 254-255.

${ }^{63}$ LUHMANN, Niklas. La sociedad de la sociedad. Tradução para o espanhol de Javier Torres Nafarrate. México: Editorial Herder, 2007, p. 501, tradução nossa. Texto original: "mientras que en el ámbito de la inclusión los seres humanos cuentan como personas, en el de la exclusión parecen importar únicamente como cuerpos. Los mecanismos simbióticos de los medios de comunicación pierden su ordenamiento especifico. La violencia física - la sexualidad, la satisfacción elemental e impulsiva de las necesidades - se liberan y se vuelven inmediatamente relevantes sin pasar por la civilización de las recursiones simbólicas; expectativas sociales más pretenciosas ya no pueden enlazarse".
} 
global concernente a tópicos extremistas, tais como o terrorismo (que reflexamente causa o anseio pela "manutenção da segurança nacional") acaba por se colocar em uma contrariedade tanto jurídica quanto política. A diferenciação entre Direito e Política, que se encontra coroada na ideia de Constituição como acoplamento estrutural entre ambos os sistemas ora tratados, cai por terra com fundamento em uma necessidade política pouco fundamentada no caso brasileiro.

Relega-se, assim, à definição pouco precisa decorrente da discricionariedade do operador administrativo, a semântica da segurança nacional - o que acaba por se configurar como excludente da fruição de direitos fundamentais e humanos do imigrante estrangeiro no Brasil, ao arrepio de uma ordem constitucional que se pretende, pragmaticamente, mais includente. Trata-se da excessiva politização da significação de postulados constitucionais mediante a legislação e a administração pública da questão - o que caracterizaria a "constitucionalização simbólica como sobreposição do sistema político ao direito". Em outras palavras,

[...] a politização adiferenciante do sistema jurídico não resulta do conteúdo dos próprios dispositivos constitucionais. Ao contrário, o texto constitucional proclama um modelo político-jurídico no qual estaria assegurada a autonomia operacional do Direito. Mas no sentido em que se orienta a atividade constituinte e a concretização do texto constitucional resulta o bloqueio político da reprodução operacionalmente autônoma do sistema jurídico. Ao texto constitucional, numa proporção muito elevada, não corresponde expectativas normativas congruentemente generalizadas e, por conseguinte, consenso suposto na respectiva sociedade. A partir da sua emissão não se desenvolve uma Constituição como instância reflexiva do sistema jurídico. $^{64}$

Eis a caracterização sistêmica da situação de relegação da Constituição ao mero simbolismo, no que tange à regulação da situação do estrangeiro no Brasil. Trata-se da não concretização das expectativas normativas propostas quando da promulgação como fundamentos - dignidade da pessoa humana, mormente - e como objetivos da República - promoção do bem de todos, sem discriminações (inclusive, no que tange à origem das pessoas) - em prol de uma centralização política do controle social pelo Estado, herdado de tempos em que a democracia sequer era considerada realidade. Democratizam-se parcialmente tanto os sistemas da Política quanto do Direito, e como reflexo disto, o simbolismo constitucional é aplicável apenas em situações em que o interesse político o demanda.

\footnotetext{
${ }^{64}$ NEVES, Marcelo. A constitucionalização simbólica. São Paulo: Acadêmica, 1994, p. 131.
} 


\section{CONSIDERAÇÕES FINAIS}

Uma análise dos vários instrumentos normativos concernentes às políticas de imigração no Brasil revela a mixofobia - relacionada ora a uma cultura legislativa inspirada na doutrina da segurança nacional (que tem no imigrante "o outro" como fonte de problemas) - e o utilitarismo - concernente ao interesse em atrair estrangeiros apenas em alusão ao interesse em sua mão de obra - como tônicas retóricas na legislação brasileira. Estas características são claramente atribuíveis a períodos em que o Brasil atravessava situações políticas de autoritarismo.

Contudo, a partir do advento da ordem constitucional de 1988, características democráticas (e democratizantes) são introduzidas na sintaxe jurídica nacional. Tais características - dentre as quais se pode destacar, principalmente no que concerne à matéria ora em comento, à inclusão do estrangeiro como pessoa humana, titular de direitos - faz com que a legislação originada em tempos passados se torne totalmente obsoleta, carente de revisão. Mas mesmo as proposições atuais para o trato normativo de estrangeiros em território nacional demonstra que a doutrina da segurança nacional remanesce em pauta, o que poderá continuar a ensejar raciocínios pautados pela discricionariedade do Executivo (principalmente dos Ministérios das Relações Exteriores e da Justiça) quando da admissão ou expulsão de estrangeiros do território nacional.

Entender a Constituição como acoplamento estrutural entre Política e Direito permite, em primeiro lugar, entender que este poderoso instrumento normativo possui recursos para se superar a legitimação da discricionariedade do Executivo e do próprio Legislativo. Isto porque, mesmo que a decisão legislativa (lei em sentido estrito) venha a referendar reminiscências do autoritarismo no ordenamento pátrio, no que tange à questão do estrangeiro (permitindo, assim, que o mero arbítrio do Executivo defina a situação jurídica de tais pessoas mediante critérios de oportunidade, apenas), pode-se identificar que o Direito também é fomentado pelos princípios e postulados da Lei Maior. Nesta senda, ainda que a Política possa decidir algo em confronto aos direitos, o Direito possui a capacidade para decidir em oposição àquela (desde que, obviamente, se esteja em uma sociedade funcionalmente diferenciada e democrática).

Há possibilidades, portanto, para que o Direito decida de forma a cada vez mais incluir o estrangeiro nas suas comunicações como pessoa humana, dotada de 
necessidades físicas e espirituais em uma sociedade global (para além das pretensões de segmentação territorialista). Direitos Humanos e Direitos Fundamentais contidos na ordem constitucional de 1988 demonstram que a entrada e/ou a permanência de estrangeiros no Brasil não se trata de questão apenas política: trata-se, isto sim, de questão de inclusão humana.

\section{REFERÊNCIAS}

BAUMAN, Zygmunt. Confiança e medo na cidade. Rio de Janeiro: Jorge Zahar, 2009.

BOLÍVIA. Constituição (2009). Constitución del Estado Plurinacional de Bolivia de 2009. Disponível em: <http:/bolivia.justia.com/nacionales/nuevaconstitucion-politica-del-estado/segunda-parte/titulo-v/capitulo-segundo/seccioni/\# articulo-220 > . Acesso em: 14 ago. 2014.

BRASIL. Constituição (1934). Constituição da República dos Estados Unidos do Brasil de 1934. Disponível em: < http://www.planalto.gov.br/ccivil_03/constituicao/ constituicao34.htm >. Acesso em: 14 ago. 2014.

BRASIL. Constituição (1937). Constituição dos Estados Unidos do Brasil de 1937. Disponível em: < http://www.planalto.gov.br/ccivil_03/constituicao/constituica037. htm > . Acesso em: 14 ago. 2014.

BRASIL. Constituição (1946). Constituição dos Estados Unidos do Brasil de 1946. Disponível em: <http://www.planalto.gov.br/ccivil_03/constituicao/constituicao46. htm $>$. Acesso em: 14 ago. 2014.

BRASIL. Constituição (1988). Constituição da República Federativa do Brasil de 1988. Disponível em: <http://www.planalto.gov.br/ccivil_03/constituicao/ constituicao.htm >. Acesso em: 14 ago. 2014.

BRASIL. Decreto-Lei $n^{0}$ 406, de 04 de maio de 1938. Dispõe sobre a entrada de estrangeiros no território nacional. Disponível em: < http://www2.camara.leg.br/ legin/fed/declei/1930-1939/decreto-lei-406-4-maio-1938-348724-publicacaooriginal1-pe.html > . Acesso em: 14 ago. 2014. 
BRASIL. Decreto-Lei $n^{o}$ 3.175, de 1941. Código Penal. Disponível em: <http:// www.planalto.gov.br/ccivil_03/decreto-lei/del3689.htm > . Acesso em: 14 ago. 2014.

BRASIL. Lei $\mathrm{n}^{0}$ 6.815, de 19 de agosto de 1980. Define a situação jurídica do estrangeiro no Brasil, cria o Conselho Nacional de Imigração. Disponível em: $<$ http://www.planalto.gov.br/ccivil_03/Leis/L6815compilado.htm > . Acesso em: 12 fev. 2014.

BRASIL. Poder Executivo. Projeto de Lei no 5.655/2009. Dispõe sobre o ingresso, permanência e saída de estrangeiros no território nacional, o instituto da naturalização, as medidas compulsórias, transforma o Conselho Nacional de Imigração em Conselho Nacional de Migração, define infrações e dá outras providências. Disponível em: <http://www.camara.gov.br/proposicoesWeb/ prop_mostrarintegra;jsessionid $=91 \mathrm{FEC} 9 \mathrm{DE} 2 \mathrm{FA} 2 \mathrm{~F} 83824 \mathrm{~F} 177 \mathrm{AC} 481130 \mathrm{EE}$. proposicoesWeb1 ?codteor $=674695 \&$ filename $=P L+5655 / 2009>$. Acesso em: 25 mar. 2014.

CHILE. Constituição (1980). Constitución política de la República de Chile de 1980. Disponível em: <http://www.camara.cl/camara/media/docs/constitucion_ politica.pdf $>$. Acesso em: 14 ago. 2014.

DIMOULIS, Dimitri; MARTINS, Leonardo. Teoria Geral dos Direitos Fundamentais. São Paulo: Revista dos Tribunais, 2007.

FREIRE, Roberto. Proposta de Emenda à Constituição $n^{0}$ 119/2011. Disponível em: <http:/www.camara.gov.br/proposicoesWeb/prop_ mostrarintegra? codteor $=947592 \&$ filename $=P E C+119 / 2011>$. Acesso em: 14 ago. 2014.

GORDO, Adolpho. A expulsão de estrangeiros. São Paulo: Espíndola, 1918.

LOPES, Cristiane Maria Sbalqueiro. Direito de imigração: o estatuto do estrangeiro em uma perspectiva de direitos humanos. Porto Alegre: Nuria Fabris, 2009.

LUHMANN, Niklas. El derecho de la sociedad. Tradução para o espanhol de Javier Torres Nafarrate, com colaboração de Brunhilde Erker, Silvia Pappe e Luis Felipe Segura. 2. ed. Cidade do México: Herder, Universidad Iberoamericana, 2005. 
LUHMANN, Niklas. La ciencia de la sociedad. Traducción de Silvia Pappe, Brunhilde Erker, Luis Felipe Segura; sob direção de Javier Torres Nafarrate. México: Universidad Iberoamericana; ITESO; Anthropos, 1996a.

LUHMANN, Niklas. La costituzione come acquisizione evolutiva. In: ZAGREBELSKY, Gustavo; PORTINARO, Pier Paolo; LUTHER, Jorg. Il Futuro dela Costituzione. Torino: Einaudi, $1996 \mathrm{~b}$.

LUHMANN, Niklas. La sociedad de la sociedad. Tradução para o espanhol de Javier Torres Nafarrate. México: Editorial Herder, 2007.

LUHMANN, Niklas. Law as a social system. Tradução para o inglês de Klaus A. Ziegert. New York: Oxford University Press, 2004.

LUHMANN, Niklas. Los derechos fundamentales como institución: aportación a la sociología política. Tradução para o espanhol de Javier Torres Nafarrate. México: Universidad Iberoamericana, 2010.

LUHMANN, Niklas. Sistemas sociales: lineamientos para uma teoría general. Tradução para o espanhol de Silvia Pappe e Brunhilde Erker; Coordenação de Javier Torres Nafarrate. México: Allianza Editorial/Universidad Iberoamericana, 1991.

LUHMANN, Niklas. Sobre os fundamentos teórico-sistêmicos da teoria da sociedade. Tradução de Eva Machado Barbosa Samios. In: NEVES, Clarissa Eckert Baeta; SAMIOS, Eva Machado Barbosa (Org.). Niklas Luhmann: a nova teoria dos sistemas. Porto Alegre: Editora da Universidade Federal do Rio Grande do Sul; ICBA-Goethe Institut, 1997.

LUHMANN, Niklas. Sociologia do Direito I. Rio de Janeiro: Tempo Brasileiro, 1983.

LUHMANN, Niklas. The self-reprodution of Law and its limits. In: LUHMANN, Niklas. Essays on self reference. New York: Columbia University Press, 1990a.

LUHMANN, Niklas. The world society as a social system. In: LUHMANN, Niklas: Essays on self reference. New York: Columbia University Press, 1990b.

LUHMANN, Niklas; DE GIORGI, Rafaelle. Teoria della società. 8. ed. Milano: Franco Angeli, 1996. 
MAGALHÃES, Juliana Neuenschwander. O paradoxo dos direitos humanos. Revista da Faculdade de Direito - UFPR, Curitiba, n. 47, p. 29-64, 2008.

NEVES, Marcelo. A constitucionalização simbólica. São Paulo: Acadêmica, 1994.

NEVES, Marcelo. A força simbólica dos direitos humanos. In: Revista Eletrônica de Direito do Estado, n. 4. Salvador, Bahia, Brasil: outubro/novembro/dezembro de 2005.

NEVES, Marcelo. Transconstitucionalismo. São Paulo: WMF Martins Fontes, 2009.

PARAGUAI. Constituição (1992). Constitución de la República del Paraguay de 1992. Disponível em: < http://www.constitution.org/cons/paraguay.htm>. Acesso em: 14 ago. 2014.

PATARRA, Neide Lopes. O Brasil: país de imigração? E-metropolis: Revista eletrônica de estudos urbanos e regionais, Rio de Janeiro, 2012.

ROCHA, Leonel Severo. Observações sobre a observação Luhmanniana. In: ROCHA, Leonel Severo; KING, Michael; SCHWARTZ, Germano. A verdade sobre a autopoiese no Direito. Porto Alegre: Livraria do Advogado, 2009.

SAYAD, Abdelmalek. A imigração ou os paradoxos da alteridade. Trad. Cristina Murachco. São Paulo: Edusp, 1998, p. 55.

SCHETTINI, Cristiana. Exploração, gênero e circuitos sul-americanos nos processos de expulsão de estrangeiros (1907-1920). Tempo [online], v. 18, n. 33, 2012.

SCHMITT, Carl. Teoria de la constitucion. Madrid: Alianza, 1992.

SCHWARTZ, Germano. O humano e os humanos nos direitos humanos. Animais, Pacha Mama e altas tecnologias. In: SCHWARTZ, Germano (Org.). Juridicização das esferas e fragmentação do direito na sociedade contemporânea. Porto Alegre: Livraria do Advogado, 2012.

SILVA, Érica Sarmiento da. A "não democracia" dos excluídos: alguns pontos da política imigratória brasileira. Logos 27: Mídia e Democracia, Ano 14, 2007. 
TEUBNER, Gunther. The anonymous matrix: Human Rights Violations by 'Private' Transnational Actors. Modern Law Review, v. 69, n. 3, p. 327-367, 2006.

VILLAS BÔAS FILHO, Orlando. Teoria dos Sistemas e o Direito Brasileiro. São Paulo: Saraiva, 2009.

URUGUAI. Constituição (1997). Constitución de la República Oriental del Uruguay de 1997. Disponível em: < http://www.constitution.org/cons/paraguay. htm > . Acesso em: 14 ago. 2014.

Recebido em: 12 de maio de 2015 Acesso em: 07 de agosto de 2015 